\title{
Prospective study of ovarian function in hysterectomised females
}

\author{
Richa S. Sankhe*, Ganesh A. Shinde
}

Department of Obstetrics and Gynecology, Lokmanya Tilak Municipal Medical College, Mumbai, Maharashtra, India

Received: 09 April 2020

Revised: 21 June 2020

Accepted: 29 June 2020

\section{*Correspondence:}

Dr. Richa S. Sankhe,

E-mail: richasankhe22@gmail.com

Copyright: () the author(s), publisher and licensee Medip Academy. This is an open-access article distributed under the terms of the Creative Commons Attribution Non-Commercial License, which permits unrestricted non-commercial use, distribution, and reproduction in any medium, provided the original work is properly cited.

\section{ABSTRACT}

Background: Hysterectomy is one of the most common operations performed in the world. The aim of this study was to determine prospectively the influence of hysterectomy on ovarian function by measuring gonadotrophin levels and studying ovarian doppler over a two-year period.

Methods: Authors conducted a prospective cohort study at the department of obstetrics and gynecology in study tertiary care center. The study was carried out over a period of two years November 2012-November 2014. Serum FSH, ovarian PI and questionnaire data were obtained at baseline and at 6 and 12 months postoperatively.

Results: There was significant difference in the mean FSH and mean PI at follow-up visits of 6 and 12 months. Patient characteristics did not contribute to the changes that were observed during the follow-up.

Conclusions: Authors conclude that hysterectomy affects ovarian function by affecting blood supply (reducing blood supply). This is reflected by increased FSH levels and increased PI values on ovarian Doppler.

Keywords: Hysterectomy, Follicle stimulating hormone, Pulsatality index

\section{INTRODUCTION}

Hysterectomy is second most commonly performed procedure in women in the reproductive age group. The benefits of hysterectomy have been frequently described and include the cessation of abnormal uterine bleeding, relief from monthly menstrual symptoms, and reduction in depression and anxiety levels. High satisfaction rates and improved quality of life scores following hysterectomy are consistently reported.

Extensive use of hysterectomy in women, along with the absence of pathology in more than $50 \%$ of women, has led to discussions of the merits of the procedure. Premature loss of ovarian function is associated with long term health risks, including heart disease and osteoporosis. $^{1}$ In particular, earlier age of surgical or natural menopause has been shown to correlate with an increased risk of cardiovascular mortality. ${ }^{2}$ The risk of cardiovascular disease in a large cohort study was doubled for women following oophorectomy. Other studies report the risk of myocardial infarction increases $50-60 \%$ in women following oophorectomy. The risk of CHD decreases $6 \%$ for each year oophorectomy is delayed after menopause and the RR was adjusted accordingly from ages 55 to 65 . Cardiovascular disease is the major cause of death in women and given the widespread use of hysterectomy in premenopausal women, this would be a major public health concern. ${ }^{3}$

The literature on the relationship between hysterectomy and the menopause is contradictory. Some studies suggest an earlier menopause, while others have not shown an association. ${ }^{4,5}$ However, there are a number of shortcomings within the published studies. Some studies have used retrospective recall of the onset of hot flushes as a marker of the menopause even though hot flushes are known to be a non-specific symptom which are not experienced by all women at the time of the menopause. Studies that have used gonadotrophin levels as a marker 
for the menopause were either retrospective, followed women for no more than a year post-surgery, failed to include a comparison group or had inadequate power to detect an effect.

As long-term use of oestrogen replacement therapy is no longer widely recommended, then it is important to know whether hysterectomy has a role in ovarian failure. ${ }^{6,7}$

The aim of this study was to determine prospectively the influence of hysterectomy on ovarian function by measuring gonadotrophin levels and studying ovarian doppler over a two-year period.

\section{METHODS}

Authors conducted a prospective cohort study at the department of obstetrics and gynecology in study tertiary care centre. The study was carried out over a period of two years. (November 2012-November 2014), after approval from institutional ethics committee. Informed written consent from the patients was taken before their participation in the study.

\section{Inclusion criteria}

- Women undergoing hysterectomy for a noncancerous condition

- Women in whom oophorectomy is not done

- Ovarian morphology normal

- Women in age group of 30-42 years

- Baseline FSH levels $<15 \mathrm{miu} / \mathrm{ml}$

- $\mathrm{BMI}<30 \mathrm{~kg} / \mathrm{m}^{2}$

- Non pregnant females.

\section{Exclusion criteria}

- Women undergoing hysterectomy for a cancerous condition

- Post-menopausal females

- Pregnancy

- $\quad$ BMI $>30 \mathrm{~kg} / \mathrm{m}^{2}$

- Patient not willing to participate

- Post-operative complications

- Patients who experienced menopausal symptoms.

Controls were patients who were hospitalised for other gynaecological procedures (other than hysterectomy). After obtaining a written informed consent, baseline FSH levels were derived by obtaining blood samples in the follicular phase of their cycle. The participants were administered a questionnaire and it included menstrual characteristics, pregnancy history, history of contraception use, menopausal symptoms, current use of medications and supplements and lifestyle characteristics like smoking and alcohol consumption.

Basal FSH levels and PI of ovarian artery was recorded using Doppler before the patients underwent surgery.
These patients were re-contacted at 6 months and 12 months post-operatively and information regarding the occurrence of any new symptoms was noted.

Doppler ultrasonography was used to assess the ovarian flow velocity waveform by measuring the PI at baseline and 6- and 12-months post operatively. FSH levels were also done at 6 and 12 months post-operatively.

\section{Parameters studied at baseline}

- Age distribution

- Marital status

- Parity

- Menstrual characteristics

- BMI

- Baseline FSH levels

- PI value on ovarian doppler

- Presence of menopausal symptoms

- $\mathrm{H} / \mathrm{O}$ medication use, drug addictions.

\section{Parameters studied at first follow-up}

- Type of hysterectomy undergoneabdominal/vaginal/laparoscopic

- Indication of undergoing hysterectomy

- FSH levels

- PI values on ovarian doppler

- Occurrence of new symptoms (eg.,: hot flushes).

In this study, after considering the inclusion and exclusion criteria, authors selected 30 patients who underwent hysterectomy as "cases" and 30 patients who underwent other gynecological procedures but had their uterus and at least one ovary intact as "control".

\section{Statistical analysis}

All the collected data was entered in Microsoft excel sheet. It was then transferred to SPSS software for statistical analysis.

Quantitative data was presented as mean and standard deviation and analysed using student's t-test. Quantitative data foe more than 2 groups was compared using ANOVA with post-hoc Bonferroni's test for inter group analysis.

Qualitative data was presented as frequency and percentage and analysed using chi-square test. p-value of $<0.05$ was considered as significant.

\section{RESULTS}

Maximum number of cases $(76.6 \%)$ as well as controls $(73.3 \%)$ were in the age group 36-40 years while the least number of cases and controls were in 41-45 years age group. $\mathrm{p}$ value was 0.25 , suggesting that two groups had comparable age distribution. 
Mean BMI in cases was 20.88 and in controls 20.73. p value was 0.6 indicating comparable BMI in both groups.

Table 1: Age wise distribution of cases and control.

\begin{tabular}{|llll|}
\hline $\begin{array}{l}\text { Age group } \\
\text { (years) }\end{array}$ & $\begin{array}{l}\text { Group } \\
\text { Controls }\end{array}$ & Cases & Total \\
\hline$<35$ & $8(26.7 \%)$ & $5(16.7 \%)$ & 13 \\
\hline $36-40$ & $22(73.3 \%)$ & $23(76.7 \%)$ & 45 \\
\hline $41-45$ & $0(0.0 \%)$ & $2(6.75)$ & 2 \\
\hline Total & $30(100 \%)$ & $30(100 \%)$ & $60(100 \%)$ \\
\hline
\end{tabular}

A total $90 \%$ of cases and $83 \%$ controls were multiparous while $3.3 \%$ of cases and none of the controls were nulliparous. $\mathrm{p}$ value was 0.5 , hence both groups had comparable parity. $\mathrm{p}$ value is 0.11 , hence tubal ligation status did not contribute to any significant changes during study $26.6 \%$ of the cases developed hot flushes, $6.67 \%$ developed depressed mood and $3.33 \%$ perceived anxiousness. None of the patients developed any symptoms in control group. $p$ value is 0.6 , hence not significant 9 out of $30(30 \%)$ developed hot flushes, 9 (30\%) perceived depressed mood, 2 developed anxiety. 1 patient developed impaired memory. No significant symptoms were seen in controls. $p$ value 0.6, not significant. $\mathrm{p}$ value was 0.44 , suggesting that FSH levels in both the groups were not statistically different at the beginning of study.

Table 2: Comparison of age and BMI between two study group.

\begin{tabular}{|c|c|c|c|c|c|}
\hline Variables & Group final & $\mathbf{N}$ & Mean & SD & p-value \\
\hline \multirow{2}{*}{ Age } & Cases & 30 & 37.43 & 2.388 & \multirow{2}{*}{0.25} \\
\hline & Controls & 30 & 36.8 & 1.883 & \\
\hline \multirow{2}{*}{ BMI } & Cases & 30 & 20.88 & 1.247 & \multirow{2}{*}{0.69} \\
\hline & Controls & 30 & 20.73 & 1.507 & \\
\hline
\end{tabular}

Table 3: Comparing parity between 2 study groups.

\begin{tabular}{|lllll|}
\hline \multirow{2}{*}{ Parity } & & Group & Total \\
\hline Nullipara & Controls & Cases & 1 \\
\hline Primi & $\mathrm{N}$ & $0(0.0 \%)$ & $1(3.33 \%)$ & 7 \\
\hline Multipara & $\mathrm{N}$ & $5(16.67 \%)$ & $2(6.67 \%)$ & 52 \\
\hline Total & $\mathrm{N}$ & $25(83.33 \%)$ & $27(90 \%)$ & $60(100 \%)$ \\
\hline
\end{tabular}

Table 4: Comparing tubal ligation status between 2 study groups.

\begin{tabular}{|lllll|}
\hline Tubal ligation & & Group & Cases & Total \\
\hline No & C & $22(73.3 \%)$ & $16(53.3 \%)$ & 38 \\
\hline Yes & N & $8(26.67 \%)$ & $14(46.67 \%)$ & 22 \\
\hline Total & $\mathrm{N}$ & $30(100 \%)$ & $30(100 \%)$ & $60(100 \%)$ \\
\hline
\end{tabular}

Table 5: Comparing the occurrence of any new symptoms at 6 months.

\begin{tabular}{|lllll|}
\hline New symptoms & & Abdominal & Vaginal & Total \\
\hline None & $\mathrm{N}$ & $13(59.09 \%)$ & $5(62.50 \%)$ & 18 \\
\hline Hot flushes & $\mathrm{N}$ & $7(31.82 \%)$ & $1(12.5 \%)$ & 8 \\
\hline Depressed Mood & $\mathrm{N}$ & $1(4.55 \%)$ & $1(12.5 \%)$ & 2 \\
\hline Anxiety & $\mathrm{N}$ & $1(4.55 \%)$ & $0(0.0 \%)$ & 1 \\
\hline Total & $\mathrm{N}$ & 22 & 8 & 30 \\
\hline
\end{tabular}

Mean FSH level in control group at first follow-up was 9.33 , in those who underwent abdominal hysterectomy was 21.32 and in those who underwent vaginal was 19.5 . $\mathrm{p}$ value was $<0.01$ suggesting that there was a significant difference between FSH levels of 2 groups at the end of 6 months (i.e., between control and study group).

Mean FSH level in control group at second follow-up was 11.03, in those who underwent abdominal 
hysterectomy was 53.86 and in those who underwent vaginal was 34.38. $\mathrm{p}$ value was $<0.01$ suggesting that there was a significant difference between FSH levels of 2 groups at the end of 12 months.

Table 6: Comparing the occurrence of any new symptoms at 12 months.

\begin{tabular}{|lllll|}
\hline New symptoms (f/u) & & Abdominal & Vaginal & Total \\
\hline None & $\mathrm{N}$ & $7(31.82 \%)$ & $2(25 \%)$ & 9 \\
\hline Hot flushes & $\mathrm{N}$ & $5(22.73 \%)$ & $4(50 \%)$ & 9 \\
\hline Depressed mood & $\mathrm{N}$ & $7(31.82 \%)$ & $2(25 \%)$ & 9 \\
\hline Anxiety & $\mathrm{N}$ & $2(9.09 \%)$ & $0(0.0 \%)$ & 2 \\
\hline Impaired memory & $\mathrm{N}$ & $1(4.55 \%)$ & $0(0.0 \%)$ & 1 \\
\hline Total & $\mathrm{N}$ & 22 & 8 & 30 \\
\hline
\end{tabular}

Table 7: FSH levels at baseline and at first and second follow-up.

\begin{tabular}{|c|c|c|c|c|c|}
\hline Variables & & $\mathbf{N}$ & Mean & SD & p- value (ANOVA) \\
\hline \multirow{3}{*}{ FSH (baseline) } & Controls & 30 & 8.67 & 2.578 & \multirow{3}{*}{0.44} \\
\hline & Abd. approach & 22 & 9.24 & 2.042 & \\
\hline & Vaginal approach & 8 & 8.1 & 1.47 & \\
\hline \multirow{3}{*}{ FSH $\left(1^{\text {st }} \mathrm{f} / \mathrm{u}\right)$} & Controls & 30 & 9.33 & 4.342 & \multirow{3}{*}{$<0.01^{*}$} \\
\hline & Abd. approach & 22 & 21.32 & 11.874 & \\
\hline & Vaginal approach & 8 & 19.5 & 9.04 & \\
\hline \multirow{3}{*}{ FSH $\left(2^{\text {nd }} \mathrm{f} / \mathrm{u}\right)$} & Controls & 30 & 11.03 & 7.425 & \multirow{3}{*}{$<0.01 *$} \\
\hline & Abd. approach & 22 & 53.86 & 29.414 & \\
\hline & Vaginal approach & 8 & 34.38 & 22.456 & \\
\hline
\end{tabular}

*Difference was significant between cases (both groups) and controls only.

Table 8: PI values at baseline and at first and second follow-up.

\begin{tabular}{|c|c|c|c|c|c|}
\hline & & $\mathbf{N}$ & Mean & SD & p- value (ANOVA) \\
\hline \multirow{3}{*}{ PI (baseline) } & Controls & 30 & 1.85 & 0.18 & \multirow{3}{*}{0.44} \\
\hline & Abd. approach & 22 & 1.89 & 0.133 & \\
\hline & Vaginal approach & 8 & 1.8 & 0.193 & \\
\hline \multirow{3}{*}{ PI $\left(1^{\text {st }} f / u\right)$} & Controls & 30 & 1.86 & 0.181 & \multirow{3}{*}{0.13} \\
\hline & Abd. approach & 22 & 2 & 0.304 & \\
\hline & Vaginal approach & 8 & 1.9 & 0.267 & \\
\hline \multirow{3}{*}{ PI $\left(2^{\text {nd }} f / u\right)$} & Controls & 30 & 1.87 & 0.177 & \multirow{3}{*}{$<0.05^{*}$} \\
\hline & Abd. approach & 22 & 2.1 & 0.44 & \\
\hline & Vaginal approach & 8 & 1.86 & 0.311 & \\
\hline
\end{tabular}

*Difference was significant between cases (both groups) and controls only.

Mean baseline PI values in control group was 1.85, in those who underwent abdominal hysterectomy subsequently was 1.89 and in those who underwent vaginal was 1.8 .

$\mathrm{p}$ value was 0.4 suggesting that there was no significant difference between PI values of 2 groups at the beginning of study.

Mean PI values in control group at first follow-up was 1.86 , in those who underwent abdominal hysterectomy was 2 and in those who underwent vaginal was 1.9. p value was 0.13 suggesting that there was no significant difference between PI values of 2 groups at first followup. Mean PI values in control group at second follow up was 1.87 , in those who underwent abdominal hysterectomy was 2.1 and in those who underwent vaginal was 1.86 . p value was $<0.05$ suggesting that there was significant difference between PI values of 2 groups at second follow-up.

\section{DISCUSSION}

The surgical stress brought about by hysterectomy may affect the ovarian blood supply and thereby may alter ovarian function. The blood supplied to the tubes and 
ovaries derives from the uterine and ovarian arteries. The ovarian artery, originating from the aorta, is present in the infundibulopelvic ligament and divided into 3 branches. The lateral branch of the ovary and the uterine artery branch, the medial ovarian branch that runs along the ovarian-uterine ligament in the mesovarium, anastomose to form the ovarian arcade. Such distribution, however, shows anatomic variations. ${ }^{8}$ This procedure would increase intraovarian pressure, damage ovarian microcirculation, and lead to ovarian failure.

The effects of hysterectomy on ovarian function remain controversial. Some studies indicate that the prevalence of ovarian failure is higher in women who undergo TAH, whereas others report no decrease in ovarian function. The advance of menopause age after hysterectomy has been hypothesized to correlate with a rise in the follicular atresia rate. The uterus would inhibit follicle depletion, and its surgical removal at reproductive age would accelerate follicular loss, suggesting a paracrine effect of the uterus, endometrium, or both on ovarian function. ${ }^{9}$ The other hypothesis, the increased prevalence of ovarian failure after hysterectomy, would result from the stretching of the vessels within the pelvic infundibulum, followed by thrombosis and a reduction in ovarian blood supply. ${ }^{10}$ To investigate such hypotheses, this study aimed at assessing ovarian blood supply before and after surgery by Doppler ultrasonography of the ovarian arteries at the follicular phase of the menstrual cycle because flow is reduced and similar in both ovaries during this period. However, immediately before ovulation and over the initial luteal phase, perfusion is greater in the dominant ovary, and both PI values and vascular impedance are reduced.

This study here is an attempt to seek the changes in the ovarian function in women undergoing elective hysterectomies for benign conditions.

Authors performed a prospective comparative study over a period of two years between a group of 30 females who underwent hysterectomy (cases) and a group of 30 females who underwent other gynecological procedures but had their uterus and ovaries intact such as prolapsed surgeries, myomectomy ovarian cystectomy etc.

Initially authors compared certain baseline descriptive characteristics of both the study groups such as age distribution, menstrual status, parity, BMI, tubal ligation done or not and the use of any medications that might affect the ovarian indices. All females with a known medical disorder or those who were on any medication were excluded from the study. All post-menopausal females were also excluded.

The age-wise distribution of cases and control were comparable with no statistically significant differences $(\mathrm{p}=0.25)$. Maximum number of patients undergoing hysterectomy were in the age-group 36-40 years with the mean age being 37.43 years. Maximum number of patients with their uterus intact were in the age group 3640 years with the mean age being 36.8 years.

All the obese females i.e., BMI >30 was excluded from the study as Obesity is known to affect ovarian function 109. While comparing the females in the study groups in relation to their BMI's, it was observed that, the mean BMI of cases was 20.88 and in controls was 20.73. p value was 0.69 , implying that both the groups were comparable with respect to their BMI status.

While distributing females according to their Tubal ligation status, it was observed that 14 cases out of 30 and 8 controls out of 30 had undergone tubal ligation prior to the study. $\mathrm{p}$ value was 0.11 , implying that tubal ligation did not contribute to any changes observed in ovarian function during the study. This was consistent with the studies performed so far studying the effects of tubal ligation on ovarian function.

While distributing females according to their parity, it was observed that majority of the females in both the groups were multiparous. Only 2 cases and 5 controls were primiparas and only 1 case undergoing hysterectomy was a nullipara. $\mathrm{P}$ value was 0.5 , implying that both the groups were comparable in terms of parity.

While distributing the women who underwent hysterectomy according to the type of hysterectomy and the indication for hysterectomy, it was found that 'Fibroid uterus' is amongst the most common benign condition for which hysterectomy was carried out $(56.7 \%)$, followed by prolapse $(26.6 \%)$ and finally Abnormal uterine bleeding (16.7\%). The most common approach for hysterectomy is abdominal followed by vaginal. Laparoscopic hysterectomy was not included in the study as 4 lap patients were lost to follow-up.

Post-menopausal females were excluded from the study (from both the cases and controls) as this study aim was to study the effect of hysterectomy on ovarian function.

The baseline FSH levels in both the cases and control group was comparable. Mean FSH levels in control group was 8.67, in those who underwent abdominal hysterectomy was 9.24 and in those who underwent vaginal was 8.1. p value was 0.44 , so the two groups were comparable. Similarly, the baseline PI values at the beginning of the study in control group was 1.89 , in abdominal group 1.85 and in vaginal group was 1.8 . p value was 0.4 , hence not significant. These patients were followed-up over a period of 6 months and 1 year. FSH levels and PI values were calculated again in both the groups to look for any differences. Mean FSH level in control group at first follow up was 9.33, in abdominal group was 21.32 and in vaginal group was 19.5. p value was $<0.01$ and hence was significant. At second followup again, p value was $<0.01$ with mean FSH levels being 11.03 in control group, 53.86 in abdominal and 34.38 in vaginal. FSH, as authors know is a marker of ovarian 
reserve and hence rising FSH levels at the end of one year implies reduced ovarian reserve as a result of hysterectomy.

Mean PI level in control group at first follow-up was 1.86, in abdominal group was 2 and in vaginal group was 1.9. $\mathrm{p}$ value was 0.13 and hence was not significant i.e., no significant changes in ovarian blood flow was noted. At second follow up again, $\mathrm{p}$ value was $<0.05$ with mean PI levels being 1.87 in control group, 2.1 in abdominal and 1.86 in vaginal. Increased PI value at the end of one year in females who had undergone hysterectomy implies reduced ovarian blood flow, which could be a reason for reduced ovarian reserve as shown by raised FSH levels.

Studying the occurrence of any new symptoms in cases showed that no significant symptoms related to menopause were observed post hysterectomy. All the females in study and control group were asymptomatic with respect to menopausal symptoms. Also, none of the patients in control group who underwent other procedures developed any symptoms post their surgery at follow-up.

To authors knowledge, there are a very few published reports of ovarian changes after hysterectomy that included a comparison of women with intact uteri. This study results are consistent with the PROOF study which listed a twofold increased risk of ovarian function after hysterectomy. ${ }^{11}$ Also, the risk was more in females who underwent unilateral oophorectomy along with hysterectomy.

Further follow-up of this study cohort could provide us long term patterns of ovarian changes among hysterectomized females and authors will be further able to justify that pattern of ovarian change is not just a phenomenon limited to the time shortly after surgery. Although this study clearly suggests an association between hysterectomy and ovarian failure, limitations to this study data must be acknowledged. Although the control women were from the same group of population, there were significant differences between the cases and controls in several baseline descriptive characteristics. Another limitation is that the females could be followed up over a period of one year only. Further follow up could have highlighted some important findings which had not developed so early. Also, ovarian volume was not studied, which could have further added to the conclusion. The small sample size of the study was also its limitation.

Using FSH as a biomarker for menopause which is specific but less sensitive was also a limitation. The medical consequences associated with ovarian failure at menopause are myriad and include higher risks for overall mortality, cardio-vascular disease, diabetes, osteoarthritis, certain forms of cancer and depression.

\section{CONCLUSION}

This study data suggested that women undergoing hysterectomy may be at particular risk for these outcomes. Hysterectomy is performed most commonly on women in their $40 \mathrm{~s}$ as they are approaching the menopausal transition. This study data showing that women undergoing hysterectomy are at considerably higher risk for ovarian failure suggest that it would be very appropriate to target them for lifestyle interventions. There is a need for improvisation in technique of hysterectomy so as to preserve blood supply to ovaries during hysterectomy.

Also, as not all women will experience overt symptoms of menopause, women who have undergone premenopausal hysterectomy may warrant closer monitoring of bone density or cardiovascular risk factors because of their possible risk of ovarian failure.

Funding: No funding sources

Conflict of interest: None declared

Ethical approval: The study was approved by the Institutional Ethics Committee

\section{REFERENCES}

1. Aloia JF, Cohn SA, Yeh K, Yuen K, Ellis K. Risk factors for postmenopausal osteoporosis. Am J Med. 1985;78:95-100.

2. Falkeborn M, Schairer C, Naessen T, Persson I. Risk of myocardial infarction after oophorectomy and hysterectomy. J Clin Epidemiol. 2000;53:832-7.

3. Van der Schouw Y, van der Graa Y, Steyerberg E, Eijkemans M, Banga J. Age at menopause as a risk factor for cardiovascular mortality. Lancet. 1996;347:714-8.

4. Siddle N, Sarrell P, Whitehead M. The effect of hysterectomy on the age of ovarian failure: identification of a subgroup of women with premature loss of ovarian function and literature review. Fertil Steril. 1987;47:94-100.

5. Menon RK, Okanofua FE, Agnew JE, Thomas M, Bell J, O'Brien PM, et al. Endocrine and metabolic effects of simple hysterectomy. Int J Gynaecol Obstet. 1987;25:459-63.

6. Anderson GL, Limacher M, Assaf AR, Bassford T, Beresford SA, Black $\mathrm{H}$, et al. Women's health initiative steering committee. effects of conjugated equine oestrogen in postmenopausal women with hysterectomy: the women's health initiative randomized controlled trial. JAMA. 2004;291:17012.

7. Hulley SB, Grady D. The WHI oestrogen-alone trialdo things look any better? JAMA. 2004;291:176971.

8. Borell U, Fernström I. The adnexal branches of the uterine artery. Acta Radiol. 1953;40:561-82.

9. Derksen JGM, Brölmann HAM, Wiegerinck MAHM, Vader HL, Heintz APM. The effect of 
hysterectomy and endometrial ablation on follicle stimulating hormone (FSH) levels up to 1 year after surgery. Maturitas. 1998;29:133-8.

10. Souza AZ, Fonseca AM, Izzo VM, Clauzet RM, Salvatore CA. Ovarian histology and function after total abdominal hysterectomy. Obstet Gynecol. 1986;68:847-9.

11. Moorman PG, Myers ER, Schildkraut JM, Iversen ES, Wang F, Warren N. Effect of hysterectomy with ovarian preservation on ovarian function. Obstet Gynecol. 2011;118(6):1271-9.

Cite this article as: Sankhe RS, Shinde GA.

Prospective study of ovarian function in hysterectomised females. Int J Reprod Contracept Obstet Gynecol 2020;9:3360-6. 